\title{
Article \\ Investigation of Noise Generated by Railway Freight Wagon Bogie Type Y25Ls(s)e-K and Proposals of Noise Reduction
}

\author{
Ján Ďungel ${ }^{1}$, Peter Zvolenský ${ }^{2}$, Juraj Grenčík ${ }^{2, *}$ (D) and Ján Krivda ${ }^{3}$
}

1 Department of Engineering Services, CEIT, a.s., Univerzitná 8661/6A, 01008 Žilina, Slovakia; dungeljan@gmail.com

2 Department of Transport and Handling Machines, University of Žilina, 01026 Žilina, Slovakia; peter.zvolensky@fstroj.uniza.sk

3 Department of Srategic Development, RETEX, a.s., U nádraží 894, 67201 Moravský Krumlov, Czech Republic; krivda@retex.cz

* Correspondence: juraj.grencik@fstroj.uniza.sk; Tel.: +421-41-513-2553

check for

updates

Citation: Ďungel, J.; Zvolenský, P.; Grenčík, J.; Krivda, J. Investigation of Noise Generated by Railway Freight Wagon Bogie Type Y25Ls(s)e-K and Proposals of Noise Reduction. Vehicles 2022, 4, 124-136. https:// doi.org/10.3390/vehicles4010008

Academic Editors:

Stephan Rinderknecht,

Philippe Jardin and Arved Esser

Received: 13 December 2021

Accepted: 1 February 2022

Published: 3 February 2022

Publisher's Note: MDPI stays neutral with regard to jurisdictional claims in published maps and institutional affiliations.

Copyright: (c) 2022 by the authors. Licensee MDPI, Basel, Switzerland. This article is an open access article distributed under the terms and conditions of the Creative Commons Attribution (CC BY) license (https:/ / creativecommons.org/licenses/by/ $4.0 /)$.

\begin{abstract}
There have been numerous attempts and investigations carried out with the objective to reduce the noise generated by railway freight wagons because noise is one of ever-present negative environmental pollution phenomena. This resulted in strong legislation requirements on noise reduction in railway transport, in the case of freight wagons, only exterior noise is a problem. However, the extremely hard metal structures of the wagons running on hard rails naturally generate high magnitudes of acoustic energy. One big initiative, especially in Germany, seeks a solution in replacement of the cast iron brake pads with the composite one which should result in so-called "silent trains". But braking is used only during a minor part of the train run, leaving most of the acoustic phenomena of the train run unaffected. In our research, we focused on freight bogies type Y25Ls(s)e-K that are used, including in Slovakia. We simulated the structural natural frequencies to predict vibrations and consequent sound generated by these vibrations. The idea was to localize the vibrations and propose possibilities of noise attenuation. The more realistic view about sound fields was obtained by practical measurements on a moving bogie. Measurements on the test track at a maintenance workshop were done by using a digital acoustic camera Soundcam. For attenuation of noise radiated by the bogie frame, acoustic silencers made from recycled porous fiber material have been applied to the bogie frame. To determine the acoustic difference, the material was applied only on half of the bogie, and then the measurements were carried out. The results showed a promising improvement in reduced noise radiation, which gives support for further research in this area with more precise simulations and more precise coating of the bogie frame as well as the proposal and measurement of noise-attenuating coatings of other structural parts of the freight wagons.
\end{abstract}

Keywords: freight wagon; noise simulation; noise measurements; noise localization

\section{Introduction}

The objective of the study was to investigate the noise sources on railway freight wagons and to propose measures for its mitigation. The focus was given to freight bogies type of Y25Ls(s)e-K that are widely used, including in Slovakia, as the extremely hard metal structures of the wagons running on hard rails generate high magnitudes of acoustic energy, so the primary noise source on railway vehicles is from wheel-rail contact. The bogies are the object of numerous experiments and studies, e.g., [1], as they are the most used type of freight bogies in Europe. The noise analysis is based on preliminary numerical simulations of bogie-frame vibrations and by localization of the vibration modes. This would be used for the proposal of placement of silencing pads made from porous fiber material that is expected to attenuate noise radiation from the surface. The efficiency of the silencers was evaluated by measurement on a test track in a maintenance workshop on a moving bogie. If the efficiency of the noise attenuation showed promising results, further 
investigation would follow aimed at more detailed noise measurements and feasible design modifications that could be used in real operation. Furthermore, not only bogies, but other wagon structural parts would be considered with the aim to achieve more complex noise reduction. One advantage of freight wagons in noise reduction is that it concerns only external noise. Also, running speeds are lower than in the case of passenger traffic. However, freight wagons' weight is much higher (up to 22.5 ton axle loads compared to about 12 ton axle lads in passenger wagons) and their structure is mostly metallic, virtually without any noise-absorbing materials, with large noise-radiating panels.

A comprehensive study on noise and vibration problems associated with railways in residential areas can be found in the study [2]. The authors declare that it is important to evaluate, understand, control, and regulate railway noise and vibration. They analyzed human responses to railway-noise exposure and railway-vibration exposure and combined them into formulation of policy guidance based on results obtained from the investigation.

Effects of exposure to road, railway, airport, and recreational noise on blood pressure and hypertension are thoroughly analyzed in the new study [3]. The EAA study [4] was carried out in that time involving 28 European Union member states. According to this study, there are about 10 million people inside urban areas and about 5 million outside urban areas affected by the noise produced by railways higher than $55 \mathrm{~dB}$, which is considered as noise pollution.

Noise emissions in the EU are discussed within the Directive 2002/49/EC of the European Parliament and of the Council [5]. The directive defines a common approach to preventing the harmful effects of environmental noise. Its objective is to provide a joint background for solving the issue of noise in the entire EU. An important statement can be found there: "EU noise-at-source legislation remains the most cost-effective means to address noise", which, in practical life, means that primary noise sources should be eliminated. The principle is simple, but real progress in this area is very difficult and each reduced decibel counts. Very often, the proposed solutions challenge the physical principles of the technical systems - e.g., wheels rolling on rail-a fundamental principle of rail vehicles, but generating the main portion of the railway transport noise.

The problems of noise annoyance caused by railway transport have been researched in numerous studies in the world, e.g., [6-9], each of them showing undesirable effects on human health. Effect or noise is mostly perceived as disturbing or annoying sound, but at higher sound-pressure levels it may cause a permanent damage of hearing (this is not in the case of railway transport).

The most effective measures to reduce the noise of trains seem to be a set of measures aimed at both reducing the noise at the source and on the propagation path, i.e., noise barriers and their combination with measures to improve rolling stock and acoustic properties of the track [10].

Comprehensive overview on European priorities and strategies for railway noise abatement, together with noise limits in European countries, can be found in [11]. The authors present the review of current European legislation on railway-noise generation as well as noise perception. They present cases, where technical measures against railway noise had been successfully applied and define the potential for further noise reduction demonstrated for high speed, passenger traffic, s-trains, locomotives, trams, freight traffic, track design, and, finally, wheels and track monitoring and maintenance. The paper also summarizes the results of the EURailNoise study.

For freight trains, a big initiative intended to reduce noise levels was aimed at replacement of iron-cast brake block with composite ones. According to [12], the application of the technical specification for interoperability relating to the 'rolling stock-noise' subsystem of the rail system in the Union ('NOI TSI') to existing wagons should significantly reduce maximum noise-emission levels. One of the most effective ways to mitigate rail noise is by retrofitting existing freight wagons with composite brake blocks. This technical solution reduces rail noise by up to $10 \mathrm{~dB}$, which represents a $50 \%$ reduction in audible noise for humans. However, this "optimistic" reduction is achieved only on the section of track 
where freight trains are braking, but most railway lines are not affected. And the second large problem is that the composite brake blocks pose safety problems. The LL-brake blocks (composite) result in a different wear and tear than other brake blocks, because composite material isolates and the heat is not dispersed properly when the train is in motion. The use of composite brake blocks had led to a transformation of train wheels and the transformed wheel surface could lead to derailment $[13,14]$. That implies the safety issues of noise reduction should be considered as well.

The proposed research was aimed at attenuation of noise radiation from freight wagons' structural components using recycled materials for noise attenuation. Noise reduction on structural components brings is effective during the whole train run, not only when braking. A synergic environmental effect of noise reduction and material recycling can be achieved. The idea of using recycled materials in noise mitigation is presented in a special issue of Sustainable Acoustic Materials [15], where a broad area of their utilisation is presented. A particular example from Slovakia can be found in [16] where the various types of recycled materials are analysed in terms of their acoustic parameters.

\section{Materials and Methods}

A good fundament for noise reduction methods can be found in [17] where a detailed overview of railway noise and vibration, its mechanisms, modelling, and means of control is presented. The book brings together coverage of the theory of railway noise and vibration with practical applications of noise-control technology at source to solve noise and vibration problems from railways. Each source of noise and vibration is described in a systematic way: rolling noise, curve squeal, bridge noise, aerodynamic noise, ground vibration and ground-borne noise, and vehicle interior noise.

One of the most commonly used methods of noise mitigation is the use of noise barriers, both in railway and road transport. Noise barriers are placed between noise source and recipient. Usually, the first step is to create noise maps for evaluation the railway noise impact of the affected area. When the noise barrier is constructed, the new noise map [18] showing reduced noise can be created, as can be seen on Figure 1. The area behind the barrier (above the black line) shows substantially lower values then without the barrier (below the black line).

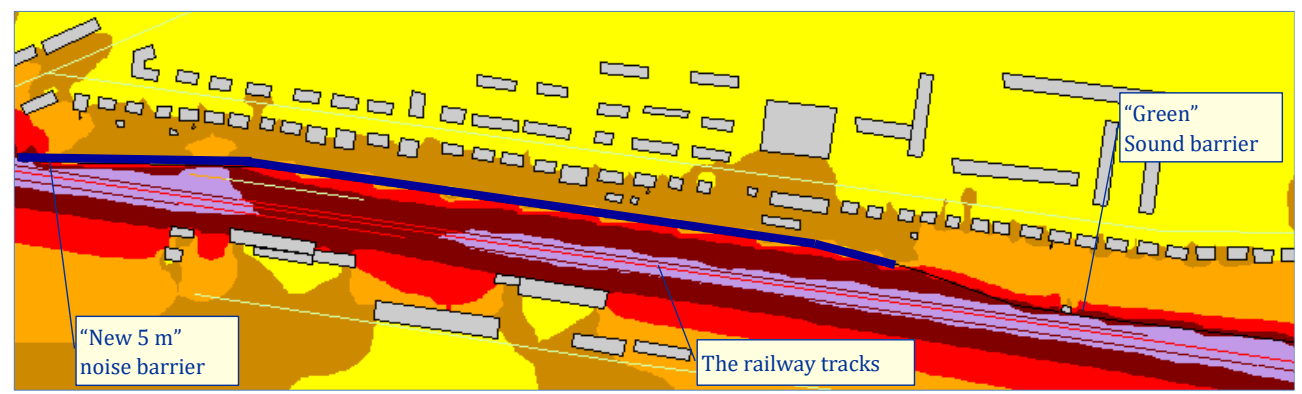

\begin{tabular}{c|ll} 
Legend: & to $45 \mathrm{~dB}$ & green \\
& from 45 to $50 \mathrm{~dB}$ & yellow \\
& from 50 to $55 \mathrm{~dB}$ & dark brown \\
& from 55 to $60 \mathrm{~dB}$ & light brown \\
from 60 to $65 \mathrm{~dB}$ & red \\
& from 65 to $70 \mathrm{~dB}$ & dark violet \\
from 70 to $75 \mathrm{~dB}$ & violet
\end{tabular}

Figure 1. Noise map-the situation with the "New $5 \mathrm{~m}$ " high-noise barrier. A visualization of the noise from the railways in the Trenčín railway station; night (22:00-6:00 h) [18]. 
In our research, we focused on noise reduction directly at the noise source. The method was based on the simulation of natural (eigen) frequencies and noise measurements of selected components (bogie frame) and, consequently, proposal of noise mitigating measures (usage of recycled materials). The authors used similar method in research and proposal of noise reduction in passenger wagons-that time we focused on internal noise, but external noise was investigated, too [19].

\subsection{Design of an Experiment to Excite Individual Bogie Components}

As the bogie moves along the track, vibrations of the bogie components are excited. The vibrations are transmitted through the structure and, simultaneously, radiated to the exterior in the form of noise. In order to reduce the overall noise of the bogie, it is necessary to attenuate the vibrations propagating in the structure, as well as the noise that has been radiated to its surroundings, because this noise is reflected several times from the hard compact metal surfaces of a vehicle structure.

Modification of the bogie design in terms of noise reduction and its commissioning is usually very time-consuming, as it has to go through an approval process. It must not affect, or even impair, the technical condition of the rolling stock on which it is installed, taking into account operation, safety, and maintenance. It must make it possible to monitor the technical condition of the rolling stock so that damage, wear, or malfunctions can be diagnosed in good time and so as to prevent failure or serious complications which could reduce safety in general.

\subsection{Excitation of Bogie Vibrations Using an Impact Hammer}

To ensure objective reproducibility and repeatability of measurements, an impact hammer was used [20], while the individual parts of the bogie were excited by vibrations in three directions. (Figure 2). The method of detection of natural frequencies of investigated structure is being used also in structural engineering, e.g., [21]. In this method, we used a sound level meter type B\&K 2250 and an acoustic camera to monitor the frequency spectrum of the radiated noise, the reverberation time, and the propagation of sound in the structure (Figure 3).

The measurement data were used in the vibration simulation bogie model created in the COMSOL Multiphysics program and for verification of the results measured in the sound experimental measurement during bogie movement.

From the acoustic module of COMSOL Multiphysics software, the most frequently used part of pressure acoustics was used, where the basic pressure acoustic effects of vibration mode shapes of the bogies were modeled. The eigenfrequency study is used to compute eigenmodes and eigenfrequencies of a linear or linearized model. In acoustics, the eigenfrequencies correspond to the resonant frequencies and the eigenmodes correspond to the normalized acoustic field at the eigenfrequencies. To determine the effect of absorption (area size, and insulation thickness), boundary conditions for the hard compact surface (bogie parts without insulation) and impedance condition for the porous layer (insulated bogie parts) were added. 


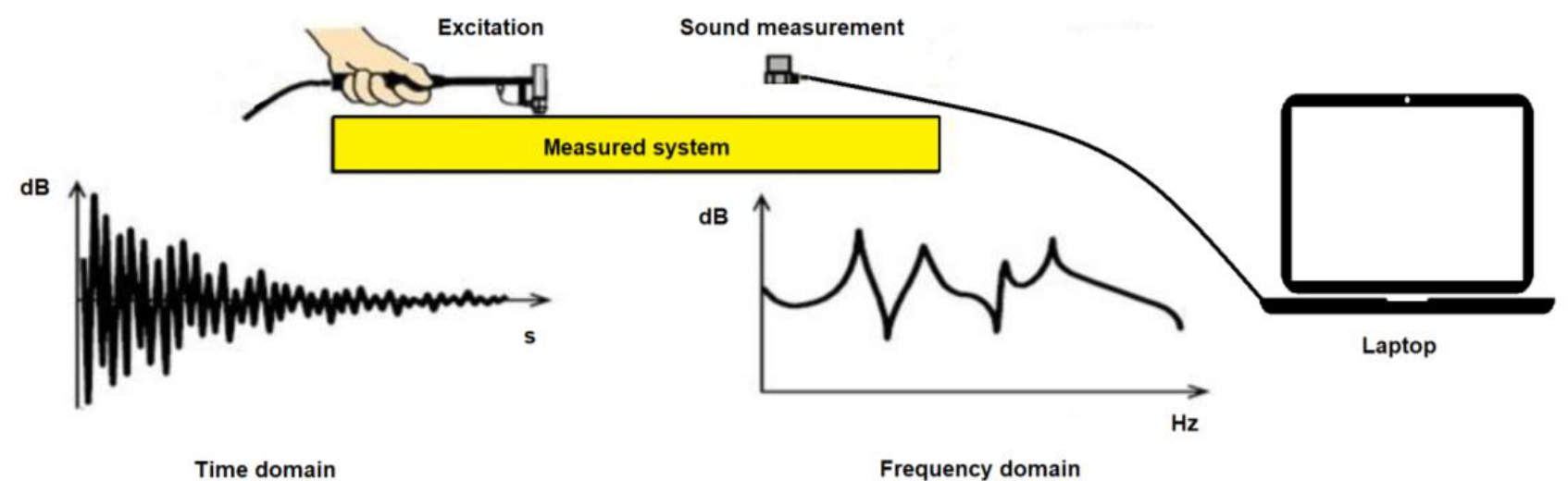

Figure 2. Sound measurements and analysis-response to vibrations generated by impact hammer.

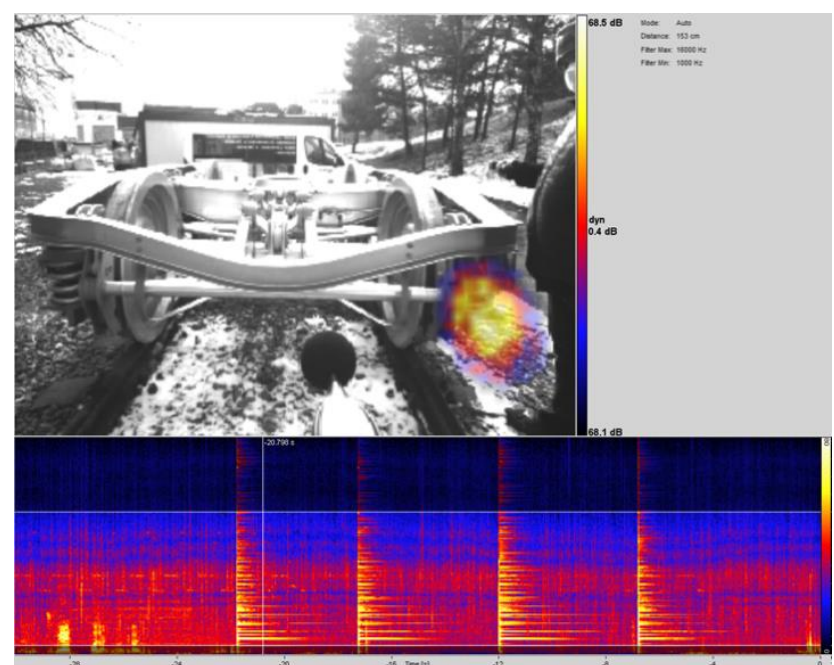

(a)

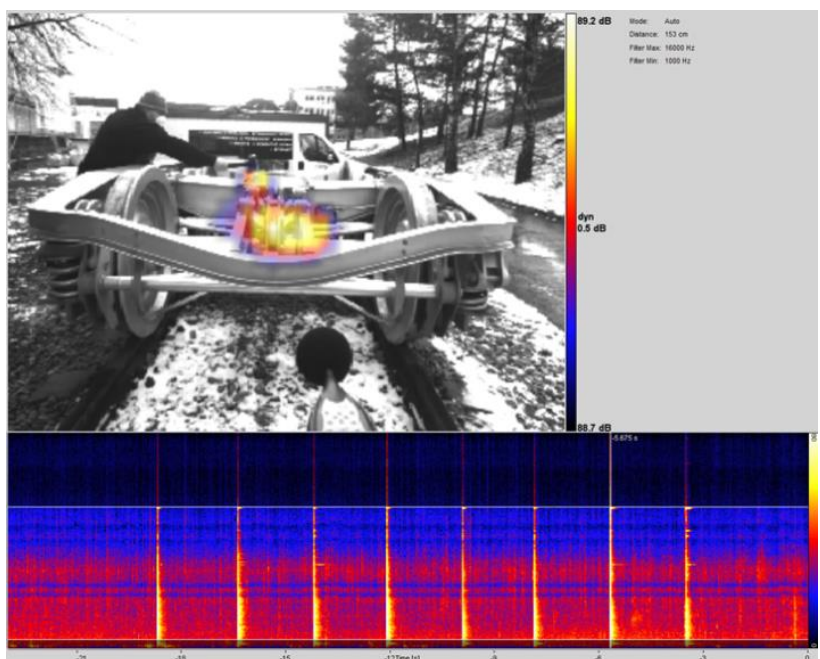

(b)

Figure 3. Recording from the acoustic camera - visualization of acoustic field radiated by excitation by impact hammer (a) wheel, and (b) main cross member. (Legend of spectrogram: horizontal axistime; vertical axis—-frequency range 1000-1400 Hz; and color scale-sound pressure level in $\mathrm{dB}$ ).

For sound field analysis and visualization, a digital acoustic camera Soundcam was used [22]. In this case, the "online beamforming" algorithm was used in the selected frequency range from $1000-16,000 \mathrm{~Hz}$. This algorithm was chosen because it is not possible to average the sound-pressure levels due to the passage of the bogie during online beamforming. To average the values and select another algorithm, the camera would have to be placed directly on an additional stand located on the chassis frame, which did not allow for the track layout

We also subjected the bogie wheels to experiments with forced vibration excitation. The built-in wheelset is clearly the dominant source of noise on the wagon bogie. The harmonic frequencies of the wheelset varied depending on whether the wheel was excited horizontally or vertically, relative to the rail.

As can be seen from the previous figures (Figure $4 a, b$ ), the most significant difference was in the length of the reverberation at the horizontal and vertical excitation. It is, therefore, clear from these measurements that, in addition to the primary contact between the wheel and the rail, the excited wheel itself is a significant source of noise, which is a direct consequence of rolling noise during the running of a train. Reducing the influence of the actual shape of the wheel frequency would reduce the noise considerably. But without modification of the bogie design, the removal of the actual vibration shapes would be difficult. 
Therefore, an available solution is to reduce the effects of this noise source in the form of absorbing noise reflections from the wagon bogie structure. To successfully absorb noise reflections from the bogie structure, it is necessary to select a suitable location and type of insulation materials.
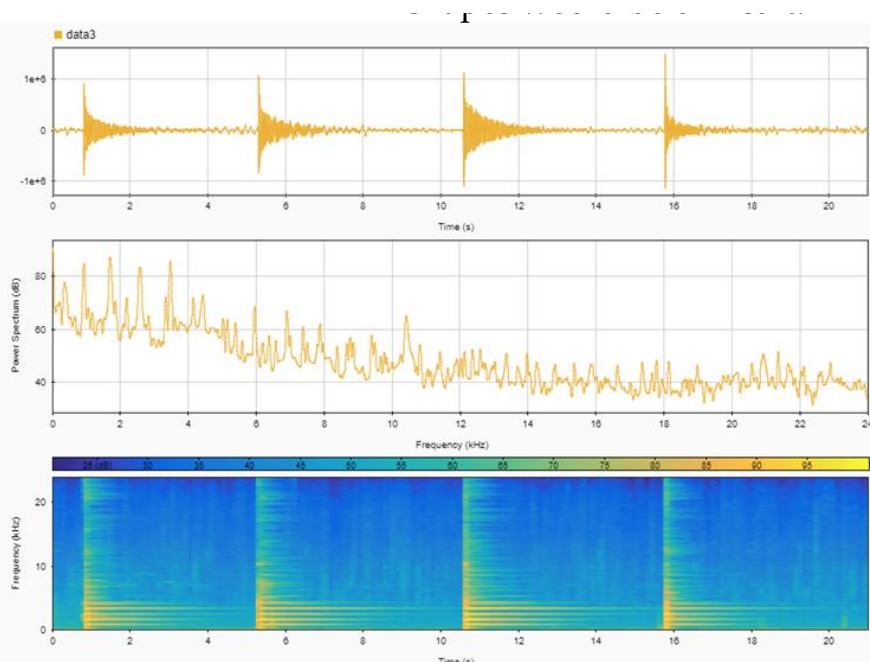

(a)
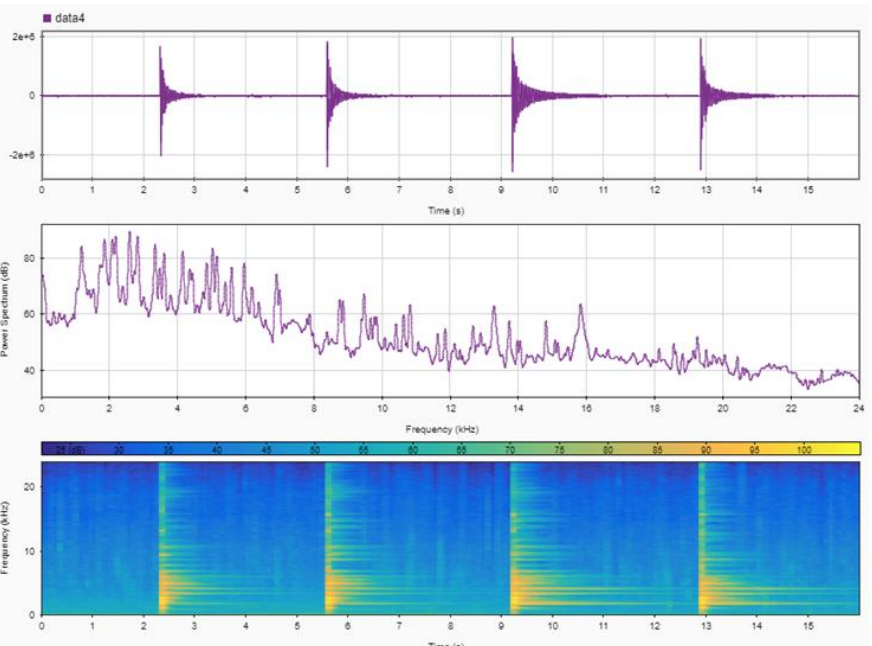

(b)

Figure 4. Railway wheelsets (a) excitation in horizontal direction); (b) excitation in vertical direction). I-impact sound (Sound pressure versus Time), II-Frequency spectrum (Sound pressure level versus Frequency), and III—spectrogram (Frequency versus Time versus Sound pressure level (color)).

\subsection{Calculation of the Natural Vibration Shapes of the Bogie Type Y25}

The natural (eigen) frequency of an undamped system is the frequency at which the systems tend to vibrate when excited and no damping element is present. A vibrating system has one or more natural frequencies, depending on whether a continuous or a discrete system is considered. A continuous system has an infinite number of natural frequencies and a discrete system has a finite number of natural frequencies.

Each eigenshape is characterized by one of its own frequencies, depending on the number of degrees of freedom of the system. The eigenshape is a motion in which all parts of this system move sinusoidally with a constant phase and frequency. The frequency at which the system vibrates at its natural frequency is called the resonant frequency. Physical objects have a set of their eigenshapes, the resonant frequencies of which depend on their structure, material, and boundary conditions (Figure 5).

After tuning the simulation model (Figure 6), acoustic material was designed for individual surfaces of the bogie structure in different bulk densities. These were chosen from the point of view of simulation, where, e.g., insulation with a specific weight of up to $35 \mathrm{~kg} / \mathrm{m}^{3}$ is suitable for the transom and insulation above $80 \mathrm{~kg} / \mathrm{m}^{3}$ for the brake frame, while the size and thickness of the insulation must not exceed the safe contour of the bogie. 


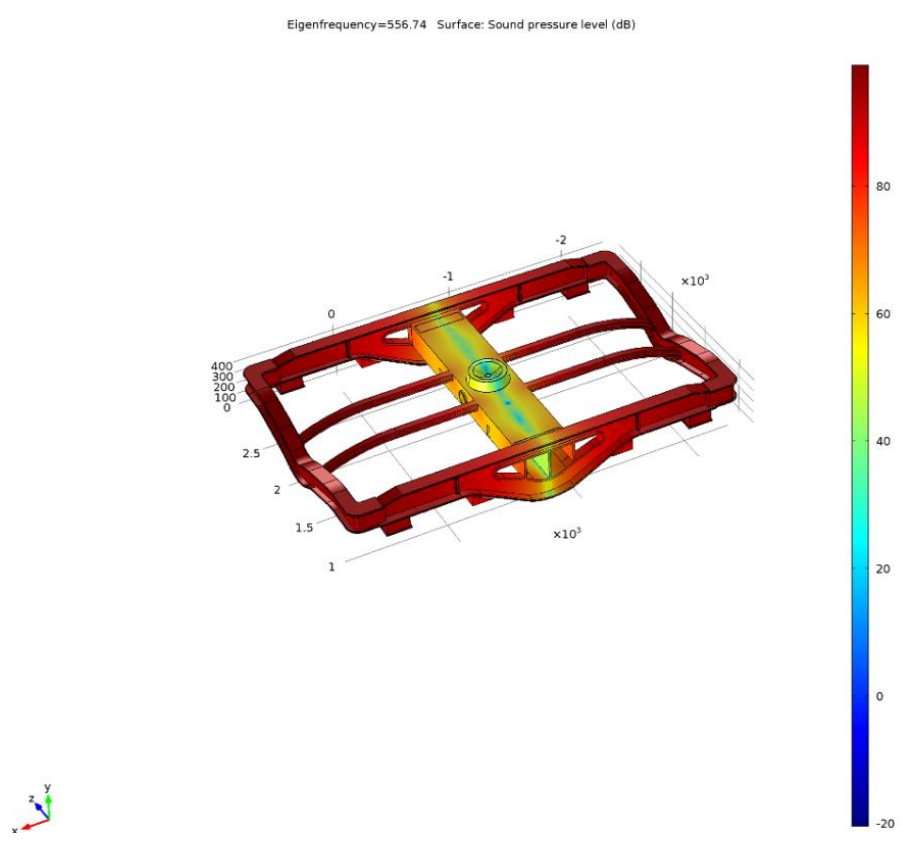

Figure 5. The calculation of sound-pressure levels at eigenfrequency 556, $74 \mathrm{~Hz}$ for the bogie frame.

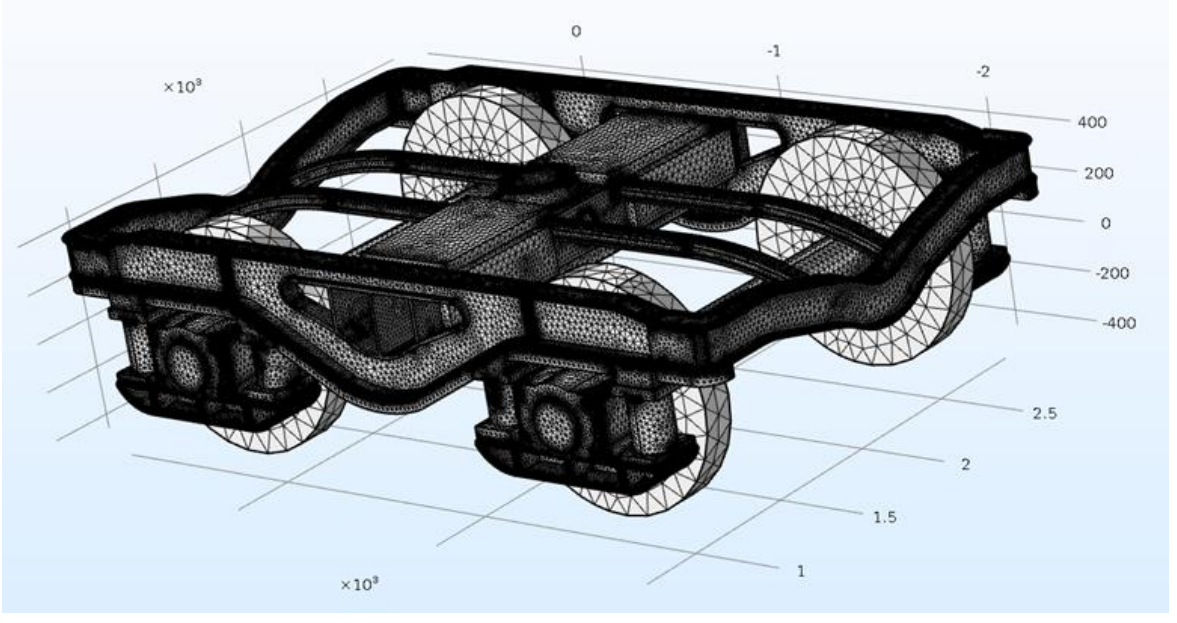

Figure 6. A mesh model of the Y25 bogie with insulation prepared in the COMSOL Multiphysics program.

The selected frequency of the eigenshape was based on the largest decrease of the sound-pressure level on the main transom after the application of the acoustic insulation. In Table 1, the first 16 calculated eigenfrequencies of the bogie type Y25 are listed.

Table 1. Calculated eigenfrequencies of freight wagon bogie type Y25.

\begin{tabular}{|c|c|c|c|c|c|c|c|c|c|c|c|c|c|c|c|c|}
\hline Frequency Number & 1 & 2 & 3 & 4 & 5 & 6 & 7 & 8 & 9 & 10 & 11 & 12 & 13 & 14 & 15 & 16 \\
\hline Eigenfrequency $(\mathrm{Hz})$ & 241.38 & 459.98 & 506.18 & 722.61 & 909.92 & 972.25 & 1220.9 & 1330.2 & 1415.7 & 1497.8 & 1504.1 & 1696.4 & 1711.0 & 1841.6 & 1711.0 & 1841.6 \\
\hline
\end{tabular}

The acoustic material used is made of recycled polyester fibers with a flame-resistant finish. Developments in the field of modern top acoustic absorbers placed on the bogie frame give us a realistic assumption that when applying acoustically absorbing material, the radiated noise to the surroundings from the bogie will be largely absorbed and not reflected. The proposed absorber in all bulk densities must meet the strictest criteria from the point of view of safety of rolling stock operation, according to EN 45545-2 + A1 [23]. When applied to the bogie, it is necessary to take into account the multiple fixations of 
the material as well as the demanding weather conditions of normal operation in traffic practice (e.g., snow, rain, and air turbulence when running the train).

\section{Results}

The main objective of the measurements was to verify the assumed noise reduction by using noise-damping materials fixed on the bogie surface.

\section{Measurement of Excited Vibrations of the Relevant Parts of the Bogie with Insulation}

An experiment was performed on this method of noise-reduction assessment, in which we compared the acoustic properties of the Y25 bogie before and after fixation of noise-absorbing materials.

A B\&K 2250 sound-level meter and a SoundCam digital acoustic camera were used for the measurement with linear frequency weighting. The experiment consisted of impact excitation the wheelset and bogie frame with a uniform force and testing the bogie passage around the acoustic camera.

We used an impact hammer to excite the structure, thanks to which we were able to strike the bogie with a uniform force so that we were guaranteed a sufficient number of measurements with the same conditions. First, the Y25 bogie was measured in its original condition and then with the insulating materials installed. The insulation was applied to the right part (half) of the bogie.

After the excitation of the frame and the wheelset, the emissions of noise propagating from the bogie were significantly reduced (Figure 7) The sound-pressure level dropped down in average by $7 \mathrm{~dB}$ and the radiation area by about 30\%. Part of the acoustic energy that would be reflected from different parts of the frame was absorbed by the insulating materials. The length of the reverberation time was also reduced, which had a further positive effect on the overall reduction of noise from the bogie.

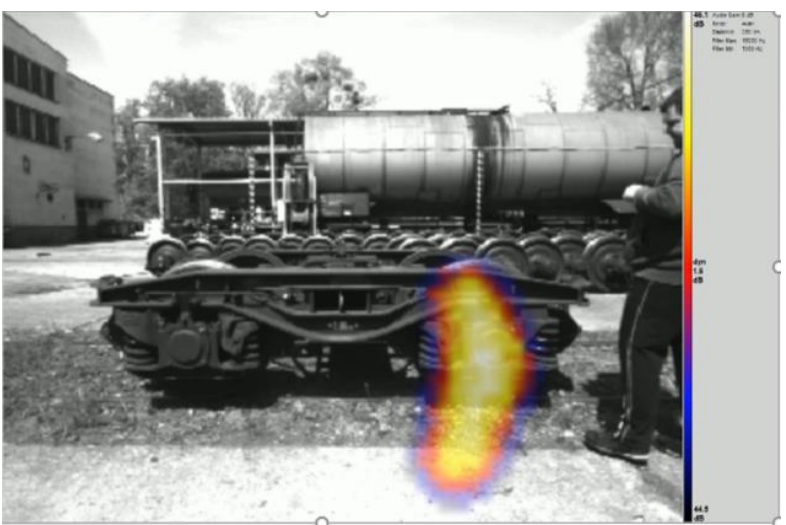

(a)

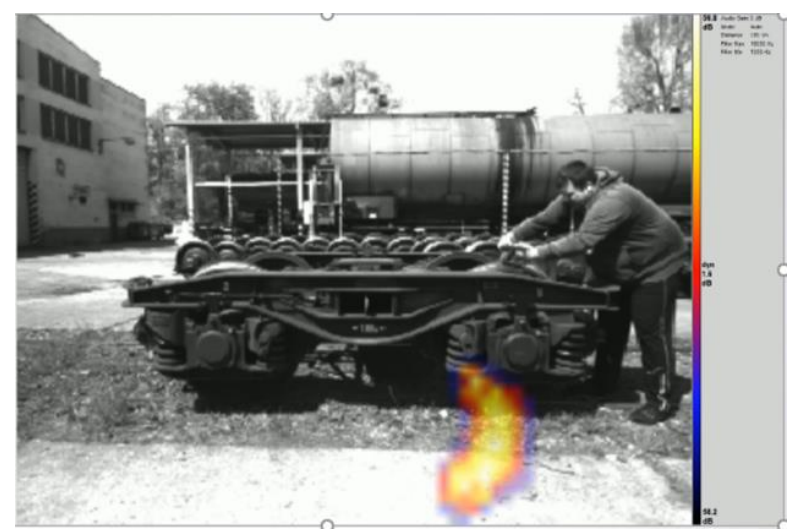

(b)

Figure 7. Recording of acoustic pressure $\operatorname{LF}_{\mathrm{MAX}}(\mathrm{dB})$ generated by wheel excitation by acoustic camera-(a) without insulation, and (b) with insulation (1 s after stroke).

Similarly, the acoustic camera was used to measure noise radiated from the bogie during its movement on a test track in the maintenance workshop (Figure 8). 


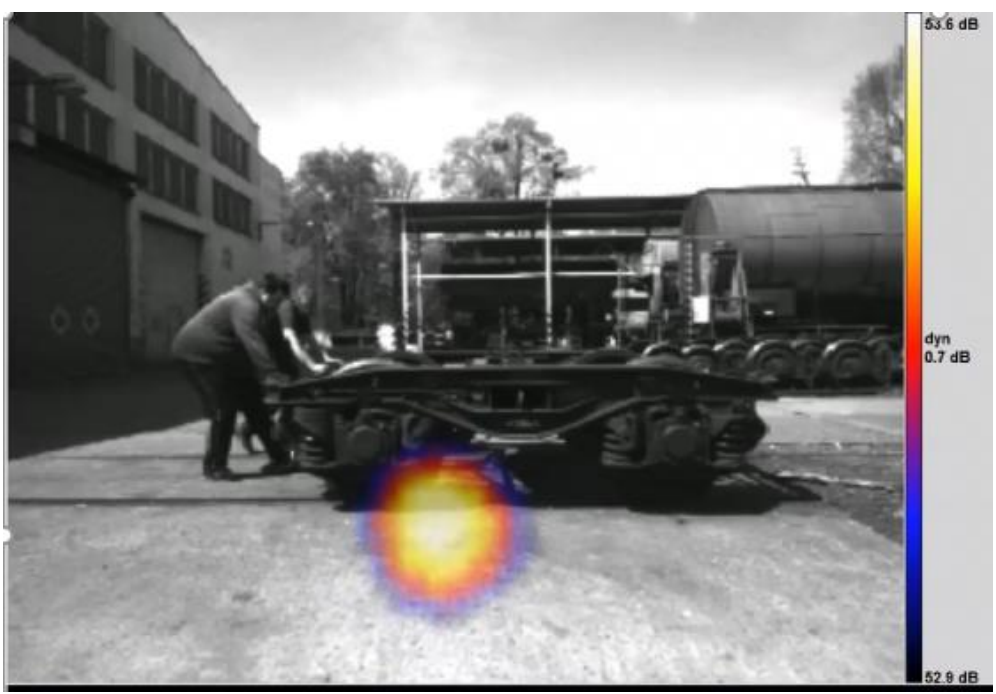

Figure 8. A picture from the acoustic camera during bogie motion (uninsulated part of the bogie on the left, insulation applied on the right).

The measurement of the bogie passage along the fixed measuring point was carried out as a comparison measurement. The height of the microphone position was $1.2 \mathrm{~m}$ above the rail. The measurement was performed on three bogies with three repetitions. A magnetic sensor mounted on an axis perpendicular to the track ensured that we had a precisely defined passage position of the wheelsets for measuring the sound pressure. As we recorded at the FAST mode, this also allowed us to compare measurements at a similar running speed $( \pm 0.15 \mathrm{~km} / \mathrm{h})$ with each other.

The images from the acoustic camera show that the dominant source of noise was the part of the bogie that was not equipped with insulation. On the part of the bogie with insulating materials installed, a considerable part of the acoustic energy was absorbed, which resulted in a reduction of noise on this part of the bogie. The average difference between the halves of the bogie was over $6 \mathrm{~dB}$ during the passage of the bogie. Uncertainty of the measurement results (standard deviation) is presented in Table 2.

Table 2. Calculation of total standard deviation of the sound measurements.

\begin{tabular}{lccc}
\hline $\begin{array}{l}\text { Standard deviation of } \\
\text { repeatability }\end{array}$ & $\sigma_{r}$ & 0.600 & $\mathrm{~dB}$ \\
Standard deviation of & $\sigma_{R}$ & 1.000 & $\mathrm{~dB}$ \\
reproducibility & $\sigma_{P}$ & 1.296 & $\mathrm{~dB}$ \\
Standard deviation of production & $n$ & 9 & - \\
Size of the sample & $\sigma_{M}$ & 2.5 & $\mathrm{~dB}$ \\
Reference standard deviation & $k$ & 0.564 & - \\
Acceptability constant & $P_{a}$ & 95 & $\%$ \\
Probability of acceptance & $u_{P a}$ & 1.645 & - \\
Quantile of the standardized & $\sigma_{t}$ & $\mathbf{1 . 6 3 7}$ & $\mathrm{dB}$ \\
distribution & & & \\
Total standard deviation & &
\end{tabular}

It should be noted that the measurements could have been affected by reflection of the solid ground surface. For better results, sound-absorbing cover of the ground surface should be added. But the research was in its first phase, with the objective to obtain informative results to prove, or not, the possibilities of the noise reduction.

\section{Discussion}

During a train running, complex vibroacoustic phenomena occur, especially in the structure of a vehicle. Since the primary main source of noise is wheel-rail contact, the principal objective of the research was to localize the vibrations on bogie, and assess and 
propose possibilities of noise attenuation. Sound measurements of excited vibrations as well as the simulation of natural (eigen) frequencies of the bogies' structural parts were done with the purpose to analyze vibrations and radiated sound from the investigated bogie.

A realistic picture of real sound fields was obtained by carrying out the practical measurements on the moving bogie. On-site measurements on the track at a maintenance workshop were carried out using a digital acoustic camera Soundcam which enables visualization of sound fields and it is possible to better localize the noise source. However, as the research is in its beginning phase, the experimental conditions were not perfect (sound reflections from the ground surface), and the results were preliminary.

For attenuation of noise radiated by the bogie frame, acoustic silencers made from special recycled porous fiber material were applied on the bogie frame. To see the acoustic difference, the material was applied only on half of the bogie, and, consequently, the measurements were carried out. Even though the measurements were carried out only as "preliminary" or "orientation", the results from verification experiments showed a promising reduction of noise radiation, which gives support for further research in this area with more precise simulations and more precise covering of the bogie frame as well proposal and measurement of noise-attenuating materials covering other structural parts of freight wagons.

From the performed simulation and experiments carried out we can conclude:

1. For lower bulk density of acoustic material, higher acoustic absorption of the material is achieved (conclusion from measurements in the impedance tube) (Figure 9);

2. For higher bulk density of the material it is possible to dampen vibrations propagating through the structure (COMSOL simulation); and

3. The application of special acoustic materials as an additive cover of the freight bogie structure reduces the amount of the radiated acoustic energy.

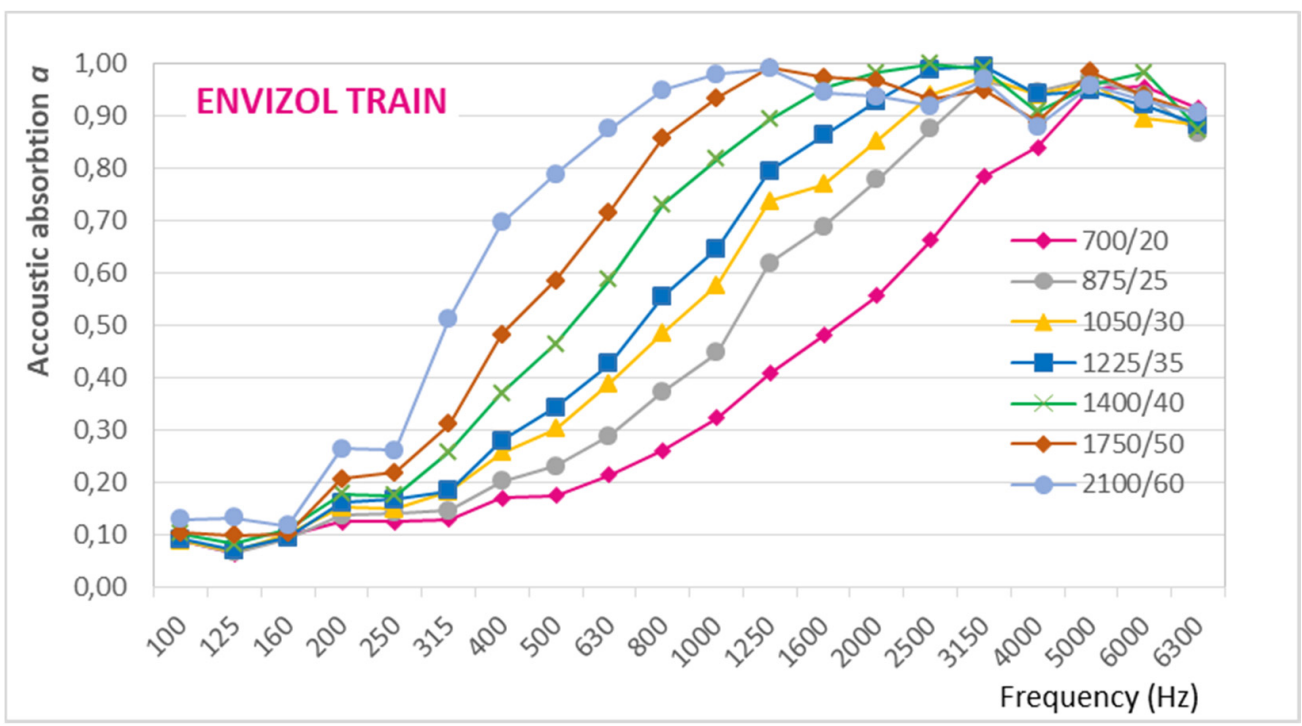

Figure 9. Acoustic absorption of the used absorbing material, according to ISO 10534-1 (Legend: meaning of numbers at material characteristic: first number: Area density $\left(\mathrm{kg} / \mathrm{m}^{2}\right)$; second number: thickness (mm), e.g., 700/20 means area density of $700 \mathrm{~kg} / \mathrm{m}^{2}$ and thickness of $20 \mathrm{~mm}$ ).

The simulation in COMSOL software before and after application of sound absorbing materials showed the reduced noise radiation (Figure 10). 


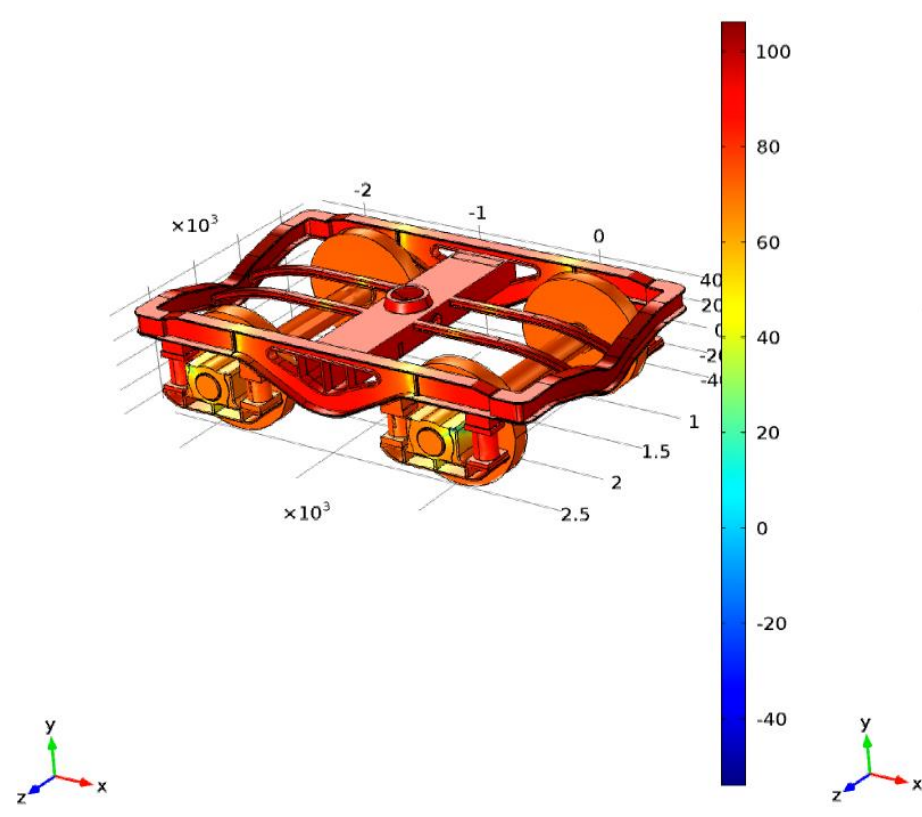

(a)

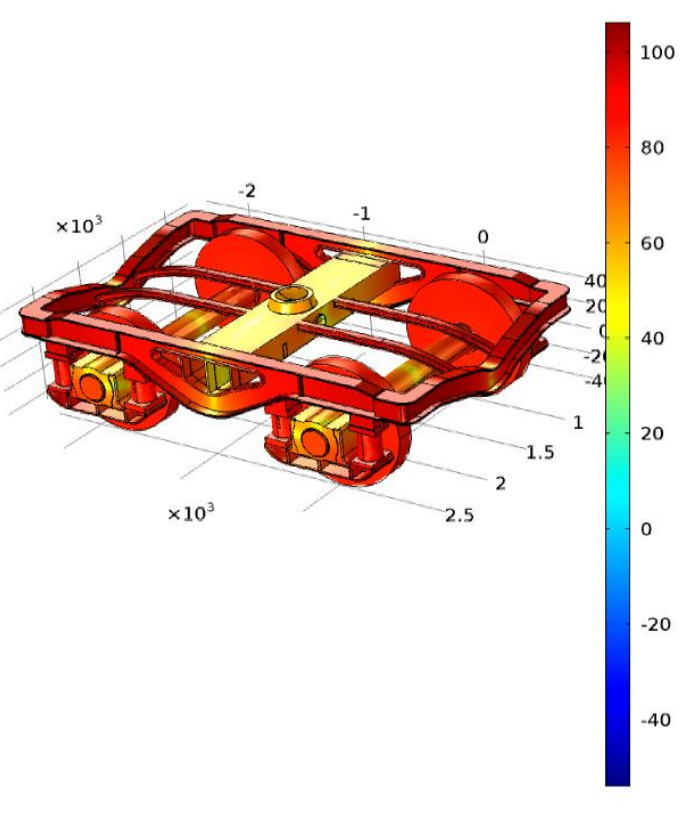

(b)

Figure 10. Simulations results for eigenfrequency of $972 \mathrm{~Hz}$; (a) before material application to main bogie member, and (b) after application.

The use of $100 \%$ recycled fibers in acoustic materials for rolling stock has a significant share in improving the indicator, which measures the share of recycled materials that return to the economy in the total material utilization and, thus, reduces the need for primary raw materials.

Today's fiber-processing technologies allow fibers with recycled materials to be treated (e.g., anti-flammable treatment) to meet the required technical and safety parameters according to EN 45545-2 in the strictest HL3 class. In this way, it is possible to increase the added value of recycled materials and increase their utilization rate in railway vehicles.

\section{Conclusions}

The article deals with monitoring the effectiveness of the proposed possibilities for reducing the noise of the Y25 type bogie in a freight wagon. Research of the acoustic properties of materials and their application in the structure of a rail freight wagon is a complex process that needs to be addressed. Relevant knowledge, especially from the results of computer simulations of the origin and propagation of the noise of railway freight wagons and research of the properties and parameters of modern acoustic materials, it is important to creatively transfer to the application in the design of freight bogies. Since computer simulations show the possibilities and predict potential, or expected, effects of the proposed acoustic modifications of the bogie, a set of verification experiments is clearly necessary, which was the focus of our research efforts. We investigated acoustic materials and their behavior when used in the specific design of the $Y 25$ type bogie.

In the system approach, it is necessary to define the required parameters of the entire freight wagon as a means of transport much more precisely, which is generally about the determination and assessment of a complex set of indicators, such as reduction of life cycle costs, operational safety and reliability, sustainability of the vehicle structure and its possible replacement or renewal, the durability of the vehicle structure, energy consumption, quality of design and its function, environmental properties (influence on the environment; reuse of recycled fibers), etc. 
The positive effect on the reduction of the noise generated by bogies gives us the assumption that the noise level of the whole wagon will decrease. This solution is suitable for both passenger and freight wagons of different types (platform, tank, etc.), where this benefit will be different for different operating speeds. From previous measurements and recalculations, we estimate that the benefit will range from 1.5 to $5 \mathrm{~dB}$ of the maximum sound-pressure level. Future research is expected in real operational modes.

Many design solutions of modern rolling stock in terms of the origin and assessment of noise emissions are mostly at the limits of current possibilities, as well as the approaches of the secondary solution (acoustic barriers, car body structure, aerodynamics, and use of materials) are relatively well developed. So any further attenuation of the noise, even if only by a few decibels, is welcome because often the permissible limits for various acoustic situations are exceeded by just a few decibels. At the same time, the use of modern materials and technologies that effectively promote recycling is of particular importance today. The rapid transfer of the results of mainly experimental research in the field of noise emissions of rolling stock into transport practice therefore brings new possibilities, tools, and approaches to effectively improve the quality of the environment.

Author Contributions: Conceptualization, J.Ď., P.Z. and J.K.; methodology, J.Ď.; software, J.Ď.; validation, P.Z. and J.G.; formal analysis, J.G.; investigation, J.Ď.; resources, J.Ď.; data curation, J.Ď.; writing—original draft preparation, J.Ď. and P.Z.; writing—review and editing, J.G.; visualization, J.D. and J.G.; supervision, P.Z.; project administration, J.Ď.; funding acquisition, J.よ̌. and J.G. All authors have read and agreed to the published version of the manuscript.

Funding: This paper is the result of the Project implementation: Operational Program Integrated Infrastructure 2014-2020 of the project: Innovative Solutions for Propulsion, Power and Safety Components of Transport Vehicles, code ITMS 313011V334, co-financed by the European Regional Development Fund.

Institutional Review Board Statement: Not applicable.

Informed Consent Statement: Not applicable.

Data Availability Statement: The data presented in this study are openly available by authors.

Acknowledgments: The authors would like to express their appreciations to the anonymous reviewers and the editors.

Conflicts of Interest: The authors declare no conflict of interest.

\section{References}

1. Dižo, J.; Blatnický, M.; Harušinec, J.; Falendysh, A. Modification and analyses of structural properties of a goods wagon bogie frame. Diagnostyka 2019, 20, 41-48. [CrossRef]

2. Peris, E.; Woodcock, J.; Sica, G.; Sharp, C.; Moorhouse, A.T.; Waddington, D.C. Guidance for new policy developments on railway noise and vibration. Transp. Res. Part A 2016, 85, 76-88. [CrossRef]

3. Petri, D.; Licitra, G.; Vigotti, M.A.; Fredianelli, L. Effects of Exposure to Road, Railway, Airport and Recreational Noise on Blood Pressure and Hypertension. Int. J. Environ. Res. Public Health 2021, 18, 9145. [CrossRef] [PubMed]

4. Nugent, C.; Blanes, N.; Fons, J.; Sáinz de la Maza, M.; Ramos, M.J.; Domingues, F.; van Beek, A.; Houthuijs, D. Noise in Europe 2014; European Environment Agency: Copenhagen, Denmark, 2014; pp. 4-62.

5. Report from the Commission to the European Parliament and the Council On the Implementation of the Environmental Noise Directive in Accordance with Article 11 of Directive 2002/49/EC; European Commission: Brussels, Belgium, 2017.

6. Bunn, F.; Zannin, P.H.T. Assessment of railway noise in an urban setting. Appl. Acoust. 2016, 104, 16-23. [CrossRef]

7. Zannin, P.H.T.; Bunn, F. Noise annoyance through railway traffic-A case study. J. Env. Health Sci. Eng. 2014, 12, 14. [CrossRef] [PubMed]

8. Licitra, G.; Fredianelli, L.; Petri, D.; Vigotti, M.A. Annoyance evaluation due to overall railway noise and vibration in Pisa urban areas. Sci. Total Environ. 2016, 568, 1315-1325. [CrossRef] [PubMed]

9. Jacyna, M.; Wasiak, M.; Lewczuk, K.; Karon, G. Noise and environmental pollution from transport: Decisive problems in developing ecologically efficient transport systems. J. Vibroeng. 2017, 19, 5639-5655. [CrossRef]

10. Talotte, C.; Gautier, P.E.; Thompson, D.J.; Hanson, C. Identification, modelling and reduction potential of railway noise sources: A critical survey. J. Sound Vib. 2003, 267, 447-468. [CrossRef] 
11. Kalivoda, M.; Danneskiold-Samsoe, U.; Krueger, U.; Barsikow, B. EURailNoise: A study of European priorities and strategies for railway noise abatement. J. Sound Vib. 2003, 267, 387-396. [CrossRef]

12. Commission Implementing Regulation (EU) 2019/774 of 16 May 2019 Amending Regulation (EU) No 1304/2014 as Regards Application of the Technical Specification for Interoperability Relating to the Subsystem 'Rolling Stock - Noise' to the Existing Freight Wagons; European Commission: Brussels, Belgium, 16 May 2019.

13. Railfreight.com. Available online: https://www.railfreight.com/technology/2018/06/12/risks-of-transformation-due-tocomposite-brake-blocks-analysed/ (accessed on 26 September 2021).

14. Martos, O.; Pravdík, K.; Schroeder, M. Task Force on the Winter Performance of Composite Brake Blocks; Report of European Agency for railways ERA1177 V 1.0; European Railway Agency: Vallenciennes, France, 2020.

15. Arenas, J.P.; Sakagami, K. Sustainable Acoustic Materials. Sustainability 2020, 12, 6540. [CrossRef]

16. Danihelová, A.; Němec, M.; Gergel', T.; Gejdoš, M.; Gordanová, J.; Sčensný, P. Usage of Recycled Technical Textiles as Thermal Insulation and an Acoustic Absorber. Sustainability 2019, 11, 2968. [CrossRef]

17. Thomson, D. Railway Noise and Vibration: Mechanisms, Modelling and Means of Control, 1st ed.; Elsevier Science: Amsterdam, The Netherlands, 2008.

18. Pultznerová, A.; Závodský, T. The noise measurement on the railways in Slovakia with focusing on the noise maps and legislation. In Proceedings of the STRAHOS 2020, 19th Seminar on Track Management, Poprad, Slovakia, 22-23 April 2020; EDIS-Publishing House of the University of Žilina: Žilina, Slovakia, 2020.

19. Ďungel, J.; Zvolenský, P.; Grenčík, J.; Leštinský, L.; Krivda, J. Localization of Increased Noise at Operating Speed of a Passenger Wagon. Sustainability 2021, 13, 453. [CrossRef]

20. Prechovatela. Available online: ahttps://prechovatela.sk/produkt/omracovaci-pristroj-pruzinova-pistol-pre-kraliky-hydinua-ryby (accessed on 5 September 2021).

21. Grosela, J.; Pakosa, W.; Sawickia, W. Experimental measurements as the basis for determination of the source of pumps' excessive vibration. Procedia Eng. 2015, 111, 269-276. [CrossRef]

22. Acoustic Camera. Available online: https:/ / www.cae-systems.de/fileadmin/CAEpage/Datenblaetter/datasheet-acousticcamerabionic-xs-56.pdf (accessed on 20 October 2020).

23. Railway Applications-Fire Protection on Railway Vehicles_-Part 2: Requirements for Fire Behaviour of Materials and Components. Available online: https://eshop.normservis.sk/norma/une-en-45545-2-2013-a1-2016-13.1.2016.html (accessed on 8 September 2021). 